\title{
2-methyl butyramide, a previously identified urine biomarker for Ascaris lumbricoides, is not present in infected Indonesian individuals
}

\author{
Ole Lagatie $^{1^{*} \mathbb{D}}$, Emmanuel Njumbe Ediage ${ }^{2}$, Jeroen A. Pikkemaat ${ }^{3}$, Yenny Djuardi $^{4}$ and Lieven J. Stuyver ${ }^{1}$
}

\begin{abstract}
Previous reports suggest that the 2-methyl butyramide and 2-methyl valeramide metabolites of Ascaris lumbricoides in urine of infected individuals could be considered as urinary biomarkers for active infection. We have developed an LC-MS method with a detection limit of $10 \mathrm{ng} / \mathrm{mL}$ using synthetic chemicals as reference material. Urine samples $(n=21)$ of infected individuals were analyzed for the presence of these metabolites, but they were not detected in any of the samples. Furthermore, the recorded ${ }^{1} \mathrm{H}$-NMR spectrum for reference 2-methyl butyramide did not match with the spectrum that was described for the Ascaris metabolite. Based on these two observations, we concluded that the urinary biomarkers that were detected for A. lumbricoides infection are not 2-methyl butyramide nor 2-methylvaleramide. New discovery efforts will be required to identify the structure of these metabolite biomarkers in urine of infected individuals.
\end{abstract}

Trial registration: Urine samples used in this study were collected as part of a clinical trial with trial number ISRCTN75636394 (12 November 2013).

Keywords: Ascaris lumbricoides, Soil-transmitted helminths, Biomarker, Urine, 2-methyl butyramide, 2-methyl valeramide

\section{Letter to the Editor}

Infection with soil-transmitted helminth (STH) parasites, such as Ascaris lumbricoides, hookworm and Trichuris trichiura, is a major health issue in large parts of the world, causing severe morbidity, especially in children. In addition to the development of new treatment options, there is also a growing need for improved diagnostics. Currently, screening (and diagnostic) procedures that are being used in the field are either based on microscopic examination of stool samples or molecular detection in stool [1-3]. Both procedures are timeconsuming, require trained personnel and specific laboratory infrastructure. However, the STH community has begun exploring opportunities to strengthen the monitoring of drug donation program impact, and

\footnotetext{
* Correspondence: olagatie@its.jnj.com

${ }^{1}$ Janssen Diagnostics, Janssen R\&D, Turnhoutseweg 30, 2340 Beerse, Belgium

Full list of author information is available at the end of the article
}

success of these monitoring efforts will most likely depend on the introduction of new diagnostic tools for non-stool based biomarkers. In a search for such nonstool based biomarkers for STH infection, the article of Hall \& Romanova is of particular interest [4]. In this paper, the authors described the identification of 2methyl butyramide (2-MBA) and 2-methyl valeramide (2-MVA) in urine as promising biomarkers for infection with A. lumbricoides. Furthermore, there seems to be a correlation with the metabolite concentration and worm burden. An extended literature search did not generate any follow-up research, neither by the authors themselves, nor by other groups who have tried to confirm these findings. Therefore, we developed a liquid chromatography tandem mass spectrometry (LC-MS) method for the quantification of 2-MBA and 2-MVA levels with a limit of quantification of $10 \mathrm{ng} / \mathrm{ml}$ urine, and using synthetic 2-MBA (Sigma-Aldrich, Overijse, Belgium) and 2-MVA (AKos GmbH, Steinen, Germany) as reference 
material. Identity and purity of the reference materials was certified by the supplier. The method showed linearity over the range from $10 \mathrm{ng} / \mathrm{ml}$ up to $20 \mu \mathrm{g} / \mathrm{ml}$ with a precision ranging from 0.7 to $4.4 \%$. Stability of $2-\mathrm{MBA}$ was investigated and it was found to be stable $(<15 \%$ difference) for $24 \mathrm{~h}$ at $4{ }^{\circ} \mathrm{C}$, room temperature and $50{ }^{\circ} \mathrm{C}$. Furthermore, this molecule was observed to be light stable $\left(4 \mathrm{~h}\right.$ at $\left.250 \mathrm{~W} / \mathrm{m}^{2}\right)$.

Since the authors described that the concentration of 2-MBA can be estimated to be about $0.006 \mathrm{~g} / 100 \mathrm{ml}$ urine/100 g wet weight of worms, we assumed that an infection with a single adult worm (weighing $c .3 \mathrm{~g}$ ) should result in urinary levels of $2 \mu \mathrm{g} / \mathrm{ml}$, which is 200 fold higher than the limit of quantification of our LCMS method. A biorepository of urine samples $(n=21$, stored frozen) collected from individuals living in the Nangapanda area, Flores Island, Indonesia, with stoolbased qPCR-confirmed infection with A. lumbricoides, or multiple infection with $A$. lumbricoides and $T$. trichiura or hookworm were analyzed for the presence of 2-MBA and 2-MVA [5]. In contrast to the published results, no detectable levels of 2-MBA or 2-MVA were found in any of the samples.

In the 1990 published report [4], the identification of the two urinary metabolites was mainly based on Proton Nuclear Magnetic Resonance ( $\left.{ }^{1} \mathrm{H}-\mathrm{NMR}\right)$ Spectroscopy. To confirm the ${ }^{1} \mathrm{H}$-NMR description, we recorded a ${ }^{1} \mathrm{H}$-NMR spectrum of the 2-MBA reference material (Additional file 1). For 2-MVA no spectrum was recorded as insufficient amounts of this reference material were available. The reference material spectrum of 2MBA was compared with the originally described spectrum but the data demonstrated that the spectrum described for the metabolite isolated from urine did not overlay with the reference spectrum of 2-MBA. Furthermore, the ${ }^{1} \mathrm{H}-\mathrm{NMR}$ spectrum we recorded matches with the theoretically expected peaks for this molecule, while this is not the case for the spectrum originally described.

In conclusion, we have shown that the urinary metabolite that was found to be a promising biomarker for infection with A. lumbricoides is not 2-methyl butyramide. The original ${ }^{1} \mathrm{H}$-NMR and infrared spectrum was not disclosed by the authors and only a brief description of the observed shifts and absorption bands is available which is insufficient to confidently deduce the chemical structure of this biomarker. We have contacted the original authors to get more information on the spectra but unfortunately none of them were able to give more information than what was available in the original publication. Hence, the question remains unanswered on the true nature of these biomarkers. Additional discovery research will be needed to isolate and characterize these unidentified metabolites from urine of STH infected individuals. If confirmed and successfully identified, these metabolites are promising biomarkers that can be used for the development of a non-stool based diagnostic monitoring tool for STH, similar to the Point-of-Care Circulating Cathodic Antigen (POC-CCA) test for Schistosoma mansoni [6, 7].

\section{Additional file}

Additional file 1: 1H-NMR Spectrum of 2-methyl butyramide. (PPTX $230 \mathrm{~kb}$ )

\section{Abbreviations}

${ }^{1} \mathrm{H}-\mathrm{NMR}$ : Proton nuclear magnetic resonance; 2-MBA: 2-methyl butyramide; 2-MVA: 2-methyl valeramide; LC-MS: Liquid chromatography coupled to mass spectrometry; STH: Soil-transmitted helminths

\section{Acknowledgements}

The authors acknowledge the support of Lieve Dillen, Luc Diels and Dirk Cleeren for discussions on LC-MS and ${ }^{1} \mathrm{H}-\mathrm{NMR}$ work. We also acknowledge Professor Maria Yazdanbakhsh, Erliyani Sartono and Taniawati Supali for kindly providing urine samples of $A$. lumbricoides infected individuals. We thank Janssen Biobank for logistic support, Will Colon for critically reviewing the manuscript and Benny Baeten and Marc Engelen from Janssen Global Public Health for programmatic support.

Funding

No funding was received for the research reported.

Availability of data and materials

All data generated or analyzed during this study are included in this published article and its Additional file.

\section{Authors' contributions}

$\mathrm{OL}$ and LSS contributed equally to the development and writing of this manuscript. ENE and JAP executed the analytical experiments. YD performed the sample collection and sample selection for this study. All authors read and approved the final manuscript.

\section{Ethics approval and consent to participate}

Human samples used in this study are from a study that has been approved by the ethical committee of the Faculty of Medicine Universitas Indonesia (ref: 549/H2.F1/ETIK/2013), and has been filed by the ethics committee of Leiden University Medical Center, clinical trial number: ISRCTN75636394. The study, its benefits and risks were explained to the population and consent forms were distributed to be signed by the subjects who were willing to participate in this study. They were informed that they can withdraw from the study at any time, for any reasons and without any consequences.

\section{Consent for publication \\ Not applicable}

\section{Competing interests}

OL, ENE, JAP and LJS are current employees of Janssen Pharmaceutica NV, being a Johnson and Johnson Company and may own stock or stock options in that company.

\section{Publisher's Note}

Springer Nature remains neutral with regard to jurisdictional claims in published maps and institutional affiliations.

\section{Author details}

'Janssen Diagnostics, Janssen R\&D, Turnhoutseweg 30, 2340 Beerse, Belgium. ${ }^{2}$ Bioanalysis, Janssen R\&D, Turnhoutseweg 30, 2340 Beerse, Belgium.

${ }^{3}$ Pharmaceutical Development and Manufacturing Sciences, Janssen R\&D, Turnhoutseweg 30, 2340 Beerse, Belgium. ${ }^{4}$ Department of Parasitology, Faculty of Medicine, Universitas Indonesia, Jakarta, Indonesia. 
Received: 16 October 2017 Accepted: 17 December 2017

Published online: 29 December 2017

\section{References}

1. Katz N, Chaves A, Pellegrino J. A simple device for quantitative stool thicksmear technique in schistosomiasis mansoni. Rev Inst Med Trop São Paulo. 1972;14:397-400.

2. Nikolay B, Brooker SJ, Pullan RL. Sensitivity of diagnostic tests for human soil-transmitted helminth infections: a meta-analysis in the absence of a true gold standard. Int J Parasitol. 2014;44:765-74.

3. O'Connell EM, Nutman TB. Molecular diagnostics for soil-transmitted helminths. Am J Trop Med Hyg. 2016;95:508-13.

4. Hall A, Romanova T. Ascaris lumbricoides: detecting its metabolites in the urine of infected people using gas-liquid chromatography. Exp Parasitol. 1990;70:35-42.

5. Tahapary DL, de Ruiter K, Martin I, van Lieshout L, Guigas B, Soewondo P, et al. Helminth infections and type 2 diabetes: a cluster-randomized placebo controlled SUGARSPIN trial in Nangapanda, Flores, Indonesia. BMC Infect Dis. 2015;15:133.

6. van Dam GJ, Wichers JH, Ferreira TM, Ghati D, van Amerongen A, Deelder AM. Diagnosis of schistosomiasis by reagent strip test for detection of circulating cathodic antigen. J Clin Microbiol. 2004:42:5458-61.

7. de Jonge N, Kremsner PG, Krijger FW, Schommer G, Fillie YE, Kornelis D, et al. Detection of the schistosome circulating cathodic antigen by enzyme immunoassay using biotinylated monoclonal antibodies. Trans R Soc Trop Med Hyg. 1990;84(6):815-8.

Submit your next manuscript to BioMed Central and we will help you at every step:

- We accept pre-submission inquiries

- Our selector tool helps you to find the most relevant journal

- We provide round the clock customer support

- Convenient online submission

- Thorough peer review

- Inclusion in PubMed and all major indexing services

- Maximum visibility for your research

Submit your manuscript at www.biomedcentral.com/submit 